\title{
Homely social practices, uncanny electricity demands: Class, culture and material dynamics in Pakistan
}

\author{
Rihab Khalid \\ Department of Architecture, \\ University of Cambridge, \\ 1 Scroope Terrace, \\ Cambridge CB2 1PX, \\ United Kingdom. \\ rk538@cam.ac.uk \\ Dr. Minna Sunikka-Blank \\ Department of Architecture, \\ University of Cambridge, \\ 1 Scroope Terrace, \\ Cambridge CB2 1PX, \\ United Kingdom. \\ mms45@cam.ac.uk
}

\begin{abstract}
This research seeks to address the gap in studies of energy consumption in developing countries from a social science perspective. The research uses Social Practice Theory (SPT) to gain better understanding of homeowners' practices and resulting electricity demand in middle-class households in Pakistan, with broader implications for other developing countries with similar climatic and socio-material contexts. Drawing on the works of Bourdieu (1984, 1997), Schatzki (2011) and Shove and Pantzar (2005), the study aims to unravel the connection between familiar domestic practices and the 'uncanny' electricity demand. Material and social constructs of 'homely' household practices related to comfort, lighting, cleanliness, cooking and ICT were studied in ten middle-class households in Lahore, Pakistan. The material arrays of the intermittent electricity provision system, modernistic prefigurations of spaces preferred by the middle-class and electrical appliances play an intrinsic role in shaping, and in turn being shaped by, everyday practices. Practices shaped by specific socio-cultural dimensions, such as social acceptance within the neighbourhood community, religious meanings, joint family structures, age disparities and gender segregation. The empirical study aims to further the conceptualisation of socially differentiated practices in domestic socio-material and cultural context of developing countries.
\end{abstract}

Key words: Social practice theory; developing countries; household practices; electricity demand 


\section{Introduction}

Rapid urbanisation and economic growth of the emerging middle-class in the developing world has resulted in their energy consumption overtaking that of the developed world, while their energy-use is expected to increase (Karakosta and Askounis, 2010; Wolfram et al., 2012). Yet policies tend to focus on energy generation (Alahdad, 2012), negating demand reduction. Taking energy demand as a for-granted need, as input for a pre-defined output (EIA, 2016), limits understanding of how and why this demand arises and evolves. This results in perception of energy as an abstract entity where the demand is seen as unpredictable and intangible, as in Freud's (1919) conception of the 'uncanny' ${ }^{1}$. Energy is an intrinsic part of the daily, familiar routines, but remains 'visibly invisible' and the demand uncertain, unfamiliar.

An argument has been made for a paradigm shift to look at energy practices as social construct rather than (rational) behaviour as in previously dominating theories building on economics and psychology, based on the attitude, behaviour and choice (ABC) model (Shove, 2010). Research on everyday routines and practices in shaping household energy demand is well established in Western energy studies (see e.g. Røpke et al 2008; Shove, 2010; Halkier et al., 2011; Warde and Southerton 2012; Shove and Walker, 2014; Schmidt and Weigt, 2015). In addition to its well-known applications in domestic energy use (e.g. Shove, 2010; Gram-Hanssen, 2010, 2014) theories of practice have been used to examine domestic DIY activities (e.g. Maller et al., 2012, Hand et al., 2005; Watson and Shove, 2005; Karvonen, 2013) and professional retrofit practices (e.g. Palm and Reindl, 2016), in Western countries. The significance of materiality in the emergence, persistence and reproduction of everyday household practices has been empirically researched in consumption studies (e.g. Kuijer et al., 2013; Strengers, 2013; Powells et al., 2014; Rinkinen et al., 2015; Foulds et al., 2017). Further, Shove (2014) argues that a better understanding of energy use as a social construct could lead to more effective and legitimate policy-making.

However, most empirical work that makes use of theories of practice is limited to Western case studies, with a limited number of exceptions that are explored in the following section (e.g. Wilhite, 2008; Sahakian, 2014; Smit, 2015, 2016 and Browne, 2016). This has led to two limitations; firstly, the pool of shared practices that the above-mentioned studies draw upon for their conceptualisation and understanding of practices are predominantly confined to Western countries. Secondly, the applicability of findings from this body of work in the context of developing world is limited by the fact that each developing country has its own unique, socially and materially structured set of inter-

\footnotetext{
${ }^{1}$ The term uncanny, with its varying nuances, has been linked with domestic spatiality and architecture in the works of Freud (1919) and Vidler (1992) respectively, depicting the transformation of something as homely and familiar as domestic architecture into something defamiliarised and strange by the spatial incursions of modernity. Although used for architecture, the essential but everchanging, visibly invisible nature of energy probed us to link it to the energy discourse.
} 
linking ideologies, cultural norms and pace of progress that shape the continuity and change of practices within the society (Abdul-Qadeer, 2006). There is limited understanding of the materiality of the housing stock in developing countries, which for example for the middle-class households is increasingly inspired by Western lifestyles - and how that materiality responds to local climate and culture.

This paper aims to expand the understanding of how practice theories can conceptualise electricity demand and household practices in the socio-material context of developing countries, taking middle-class households in Lahore, Pakistan, as case-study. Based on semi-structured, in-depth interviews and observations in the households, the research aims to answer the following questions in the case study context: How do the material arrangements adapt to and shape everyday household practices and the resulting electricity consumption? What role do the socio-cultural dynamics play in structuring homeowners' daily practices and the resulting electricity consumption?

Literature review is presented in section 2 and the empirical study is described in section 3. Section 4 describes the findings and conclusions are drawn in section 5.

\section{Theories of practice and energy use}

Practice theories provide an integrated framework to conceptualise a duality of social structuring: structures condition human activity, which through their recursive reproduction through practices, reconstitute these very structures (Giddens, 1984). According to Giddens (1984), practices are based on people's shared understandings (authoritative or allocative 'rules') of the world. The 'practice turn' in social theory led to conceptualisation of social practices as the central unit of analysis, taking practices as the site where 'understanding is structured and intelligibility articulated' (Schatzki, 1996, p. 12). Compared to ideas dominating in disciplines like psychology or economics, practice theories divert attention away from individuals' (rational) decision-making towards wider societal structures. Practice theories suggest that our common practices are not shaped by a large number of individuals acting independently but are dictated by interconnected sets of social norms, infrastructure, embodied habits and understandings. The notions of 'practice theory' and 'practices' have several different meanings in social science but their use in energy research has been based on Schatzki $(1996,2001)$ and Reckwitz (2002a) whose work has been introduced to energy studies by Warde (2005) and Shove (2012) and applied and elaborated on by researchers like Gram-Hanssen $(2010,2014)$. While practice theories are applied to empirical studies, it should be noted that they have been primarily interested in the mechanisms of how a society works and not developed as a convenient framework for empirical studies in energy demand 
reduction. They can, therefore, be more useful as a heuristic rather than representational model (Galvin and Sunikka-Blank, 2016).

To date, theories of practice consist of varied concepts and frameworks defined by authors of diverse disciplines (see e.g. Gram-Hanssen (2011) and Shove and Walker (2014) for summary of these definitions) but the models of Shove and Pantzar (2005) and Gram-Hanssen (2011) are most commonly used in energy studies. Material dimension associated with practices takes a central place in all energy consumption studies. Gram-Hanssen (2011) focuses on technology as the material constituent of practices in societal transitions. Shove and others $(2005,2012)$ adopt a wider definition and consider materiality as an all-encompassing whole and for this reason, the framework by Shove and Pantzar (2005) was adopted in this research. Their conceptualisation presents practices as the interconnected relations between three elements: materials (including objects, infrastructures, built environments, tools, hardware and the body itself), meanings (representing the ethos, norms, aspirations, ideologies, symbolic significance, perceptions and the reasoning in carrying out practices) and competences (understanding, know-how, the learnt bodily and mental routines) (Shove et al., 2012, p. 25).

Contrary to Giddens, Schatzki (1990; 1997; 2002) whose approach Shove's model (Shove and Pantzar, 2005) is based on, sees habituated skills, practices, instead of 'rule'-following, as an explanation of human actions. For Schatzki, practices are organised through three dimensions: practical understanding, explicit rules and teleoaffectivity while socio-economic aspects receive less attention, as also in the work of Reckwitz (2002; 2012). Consequently, cultural capital and socioeconomic factors, and how these influence the formation of practical consciousness, have not been at the core of practice theory studies in energy research. In order to include socio-economic aspects and their relation to practices (and compare rich and poor countries), this study also draws from the work of Bourdieu (1977, 1984). As one pioneer of practice theories, Bourdieu provided an understanding of practices within the context of the individuals' inherent disposition, 'habitus', available means or resources, 'capital' and the social arena, 'field'. For Bourdieu, social differentiation of practices is a key theme. In addition to dispositions formed by past experiences, individuals draw upon socio-economic and cultural resources, demarcated as 'capital'. The various forms of capital are both embodied and objectified in individuals' pursuit of class distinction and desirable social standing and together, these play a central role in defining their positioning and performance of practices in the social world. Bourdieu (1984, p. 101) defined practice as:

$$
[\text { (habitus) }(\text { capital) }]+\text { field }=\text { practice }
$$

Using Bourdieu's conceptualisation helps to understand class as not just formed of economic capital, but also of cultural and social capacities. Bourdieu distinguishes between three forms of 
cultural capital: institutionalised, embodied and objectified (Bourdieu, 1997). The concept of how class registers cultural divisions continues to be applied in socio-cultural studies (see e.g. Bennett et al., 2009; Savage et al., 2013; Purhonen et al., 2014; Darmon and Warde, 2016) However, Bennett et al.'s (2009) extensive work on cultural and class distinction in Britain warrants additional forms of capital to supplement these somewhat restrictive categories. Class and taste have been little studied in the context of developing countries and in this study, efforts were made to understand middle-class household preferences and aspirations in the interviews.

Social and cultural paradigms within which practices are undertaken 'constitute a site of resistance and challenge' (Halkier et al., 2011, p. 9) involving adjustment, interpretation and alteration - a concept that demands particular attention in studies of consumption in different contexts. Warde (2005) contends that practices are internally differentiated as the practitioners in different situations carry out the same practice differently. Such differentiations are further compounded by the social differentiation of the same practices in different ethnic groups (Halkier and Jensen, 2011; Maller, 2011) and between different cultural dispositions (Wilhite et al., 1996; Matsuhashi et al., 2009; Rinkinen and Smits, 2016) or even between cross-national contexts (Darmond and Warde, 2016). In addition, the individual acts as the 'intersection point' (Warde, 2005, p. 144) of many different practices. The study of single practices negates the significance of the connections, conjunctions, alliances and conflicts that exist between simultaneously occurring or existing practices (Hargreaves, 2011; Rinkinen and Smits, 2016). Study of such bundles of loosely knit or complexes of more tightly knit practices (Shove, et al., 2012) or plenums (Schatzki, 2011) highlight the interlinking nature of everyday practices. According to Schatzki (2011), social phenomena are slices of a plenum of linked arrangements and practices through five types of relations: causality, prefiguration, constitution, intentionality and intelligibility. The notion of prefiguration becomes particularly important in a unique socio-cultural and geographical context as it describes the role of the present (plenum of linked practices and arrangements) to changes in the future. Most studies of practices focus only on a single practice such as cooking (e.g. Halkier and Jensen, 2011) or laundering (e.g. Higginson et al., 2015). However, to get a comprehensive understanding of overall energy demand, a deeper understanding of interlinking compound practices is required, with an acknowledgement that practices are taking place within a socio-spatial context, such as a household or work place. This study aims to understand the total electricity consumption within a household and therefore interlinking household practices (comfort, lighting, cooking, cleaning and ICT) are studied.

Socio-technical studies of electricity consumption, in particular from a practice-based perspective, in developing countries have been limited. Exceptions include Wilhite's (2008) work on 
consumption and societal transformation in Southern India, and Sahakian's (2014) research on increasing practices of urban air-conditioning in four mega-cities in Southeast Asia, due to globalisation. This has been corroborated by Smits' (2015) take on the conflicts between modernity and sustainability in Southeast Asian energy transitions. Browne's (2016) review of the history and patterns of water consuming practices in China calls for an extension of research work in the Global South, to form an enriched understanding of consumption from the socially differentiated practices that are bound by their context-dependent cultural, material, social and political realities. Since most contemporary empirical studies of practice are located within the socio-cultural context of Western countries (see section 1), the relation between social practices, class and culture in studies of consumption in developing countries has not been much explored.

This study seeks to fill this knowledge gap by taking a practice-based approach to demystifying the 'uncanny' electricity demand of middle-class households in developing countries, focusing on Pakistan. It identifies the material and social structures that shape everyday, 'homely' household practices. This research sets its theoretical foundations in the work of Shove and Pantzar (2005), drawing from Bourdieu (1977, 1984, 1997) and Schatzki (2011). By taking a combined account of overall electricity consumption through various interlinked household practices, the study seeks to overcome the limitation of studying practices in isolation.

\section{Methodology}

The investigation of daily household practices was conducted in a case-study of ten middle-income households in Lahore, Pakistan. Pakistan is an interesting case-study as it has been identified among top ten countries most vulnerable to climate change (Kreft et al., 2015); it faces escalating trends in urbanisation and ever-increasing gaps between energy demand and supply (HDIP, 2015). In Pakistan, as in many developing countries with similar socio-economic and climatic constraints, the common response to demand management is electricity load-shedding, where power is shut down intermittently for 6-8 hours in urban centers as a last resort to overcome the energy gaps.

The sample group represents the middle- to upper-middle-income households in Lahore, Pakistan. Ownership of urban housing stock in Pakistan is concentrated in the middle and upper-income bracket and constitutes the bulk of the domestic energy demand (Shaikh, 2016). Lahore is the second largest city of Pakistan, with an estimated population in excess of 10 million. Lahore was selected as a case-study due to a representative group of middle-class households and its' on-going expansion with development of several new housing schemes that cater to middle and upperincome groups. The dominating housing typology, usually located on a plot size of $420 \mathrm{~m}^{2}$ (locally known as "1 kanal") was chosen as it represents the most common plot-size within Lahore 
Metropolitan Area and caters to the selected income group (HIES, 2015). Homes built on these plots are usually two-storey detached masonry houses, with four to five bedrooms along with one or two rooms for in-house staff. Most households have joint or single family structures usually accommodating five to ten occupants. Efforts were made to ensure that the case-study sample would be a good representative of varying socio-demographic characteristics embodied within the specified income group, representing a range of family structures, number of occupants, education level and age.

In-depth semi-structured interviews were conducted in ten case-study households. Semi-structured interviews provided an opportunity of heterogeneity in conversation, much more nuancedly enriched than the forced homogeneity of quantitative surveys. A full list of the interviews, with pseudo names for participants and household demographics are given in Table 1. A total of 21 persons were interviewed, a maximum of three from a single household. All interviews were conducted within the houses of the occupants in July and August, 2016, and lasted from 60-100 minutes. The interviews were followed by a guided tour of the house, accompanied by photography, general observations and informal conversations. Home tours as a method for researching practices is now recognised as a valuable means of participant engagement with spatiomaterial aspects of their practices (Powells et al., 2014). In the present research, the walk-through tours helped substantiate the interview findings, make links between spatial arrangements of practices and in certain cases brought to light elements of the homeowners' practices that had not been brought forth during the interviews.

To get a comprehensive understanding of overall electricity demand in households, practices related to the following areas that define households' electricity consumption were analysed; comfort (including space cooling/heating and ventilation), lighting, cleanliness (including house cleaning and laundering), cooking (including food preparation, food storage and dining), and ICT/digital entertainment. Bathing practices were not included in the study, as it does not directly result in electricity consumption in the present case. The selection of practices related to these areas was guided by the work of Gram-Hanssen (2008) with the aim of acquiring a holistic understanding of the household daily routines and practices that result in overall electricity consumption in households, hence negating the shortcomings of investigating practices in isolation.

All interviews were recorded, translated from Urdu to English, and transcribed. The interview findings were coded and analysed using NVivo 11 (a type of CAQDAS-Computer Aided Qualitative Data Analysis Software), which facilitated the coding process by providing structure and organisation to the analysis work. In the first instance, provisional codes were used to collect data for each practice. Once the interviews were transcribed and deductively coded, first cycle 
coding was done. Eclectic coding was used for second cycle coding, which were then peerreviewed for elimination of researcher bias and validation. Finally, major themes were identified within the context of practice theories.

Table 1: Household and Interview participant demographics

\begin{tabular}{|c|c|c|c|c|c|c|c|c|c|}
\hline 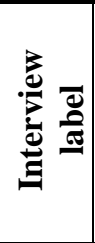 & 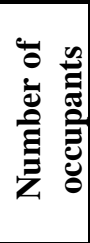 & 㟒导 & 总 & 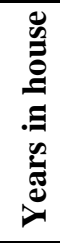 & 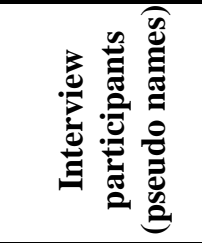 & 苾 & 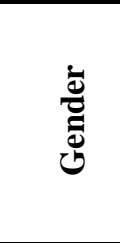 & 氖 & 离 \\
\hline $\mathbf{A}$ & \multirow{3}{*}{7} & \multirow{3}{*}{ Joint Family* } & \multirow{3}{*}{ Self-built } & 11 & Mr. Asim & $60+$ & Male & Self-employed & $\mathrm{BA} / \mathrm{BSc}$ \\
\hline $\mathbf{A}$ & & & & 11 & Mrs. Asim & $51-60$ & Female & Housewife & $\mathrm{BA} / \mathrm{BSc}$ \\
\hline $\mathbf{A}$ & & & & 11 & Mr. Arif & $20-30$ & Male & Self-employed & $\mathrm{BA} / \mathrm{BSc}$ \\
\hline B & \multirow[t]{2}{*}{4} & \multirow[t]{2}{*}{ Single Family } & \multirow[t]{2}{*}{ Self-built } & 19 & Mrs. Bashir & $41-50$ & Female & Housewife & $\mathrm{BA} / \mathrm{BSc}$ \\
\hline B & & & & 19 & Ms. Bisma & $20-30$ & Female & Student & MBBS \\
\hline $\mathbf{C}$ & \multirow{3}{*}{5} & \multirow{3}{*}{ Single Family } & \multirow{3}{*}{ Bought as built } & 20 & Mr. Cyrus & $31-40$ & Male & Unemployed & MA/MSc \\
\hline $\mathrm{C}$ & & & & 20 & Mrs. Chishti & $51-60$ & Female & Housewife & $\mathrm{BA} / \mathrm{BSc}$ \\
\hline $\mathrm{C}$ & & & & 20 & Ms. Cemaal & $20-30$ & Female & Student & MPhil \\
\hline D & \multirow{3}{*}{9} & \multirow{3}{*}{ Joint Family } & \multirow{3}{*}{ Self-built } & 15 & Mrs. Dawood & $51-60$ & Female & Housewife & MA/MSc \\
\hline D & & & & 15 & Ms. Duriya & $51-60$ & Female & Housewife & $\mathrm{BA} / \mathrm{BSc}$ \\
\hline D & & & & 8 & Ms. Dua & $31-40$ & Female & Housewife & MA/MSc \\
\hline $\mathbf{E}$ & 11 & Joint Family & Self-built & 24 & Mrs. Ejaz & $51-60$ & Female & Housewife & $\mathrm{FA} / F S c^{\dagger}$ \\
\hline $\mathbf{F}$ & \multirow{2}{*}{7} & \multirow{2}{*}{ Joint Family } & \multirow{2}{*}{ Self-built } & 18 & Mrs. Furqan & $51-60$ & Female & $\begin{array}{l}\text { Housewife/ } \\
\text { Charity worker }\end{array}$ & MA/MSc \\
\hline $\mathbf{F}$ & & & & 18 & Mr. Fareed & $31-40$ & Male & $\begin{array}{l}\text { Full-time } \\
\text { Employed }\end{array}$ & MA/MSc \\
\hline $\mathbf{G}$ & 5 & Single Family & Bought as built & 8 & Mrs. Gulzar & $31-40$ & Female & Housewife & $\mathrm{BA} / \mathrm{BSc}$ \\
\hline $\mathbf{H}$ & \multirow[t]{2}{*}{6} & \multirow[t]{2}{*}{ Single Family } & \multirow[t]{2}{*}{ Self-built } & 22 & Mr. Harris & $51-60$ & Male & Self-employed & $\mathrm{BA} / \mathrm{BSc}$ \\
\hline $\mathbf{H}$ & & & & 22 & Mrs. Harris & $51-60$ & Female & $\begin{array}{l}\text { Housewife/ } \\
\text { self-employed }\end{array}$ & $\mathrm{BA} / \mathrm{BSc}$ \\
\hline $\mathbf{I}$ & \multirow[t]{2}{*}{8} & \multirow[t]{2}{*}{ Joint Family } & \multirow[t]{2}{*}{ Bought as built } & 2 & Mrs. Imran & $51-60$ & Female & Housewife & $\mathrm{MA} / \mathrm{MSc}$ \\
\hline $\mathbf{I}$ & & & & 1 & Ms. Izza & $20-30$ & Female & Housewife & MA/MSc \\
\hline $\mathbf{J}$ & \multirow[t]{2}{*}{11} & \multirow[t]{2}{*}{ Joint Family } & \multirow[t]{2}{*}{ Self-built } & 19 & Mrs. Jamal & $51-60$ & Female & Housewife & $\mathrm{FA} / \mathrm{FSc}$ \\
\hline $\mathbf{J}$ & & & & 19 & Ms. Jamila & $20-30$ & Female & Student & MA/MSc \\
\hline
\end{tabular}

* Indicating more than one nuclear family living within the same house, e.g. main couple's family living together with the married son, his wife and children.

† Pakistan's academic degree for Higher Secondary Certificate equivalent to GCE A-Levels in UK.

This study is based on a case-study approach (Yin, 2014) and due to the limited sample sizes the paper does not aim to statistically generalise its' findings, but focusses on interviewee narratives and understanding the characteristics of daily practices, how they relate to materiality and could be harnessed in policies, drawing from the work of Shove and Pantzar (2005) and Bourdieu (1977, 
1984) in relation to practice theory as discussed in the previous section. Focusing on ten households helped to ensure that detailed examination would be possible through in-depth interviews and observation. Strauss and Corbin (1998) contend that although data saturation is probably never achieved, detailed coding and inspection of at least ten interviews or observations are required for theory structuration - this is also a convention in the field of qualitative energy studies (see e.g. Galvin, 2015). For the present study, it is argued that the sample of ten was found to be sufficient as, although no claims of statistical generalisationa are made, the case suffices to identify key characteristics of household practices that differ from those in Western households and start a conversation of how they could potentially be addressed in policies. In the last few interviews less new themes emerged and the narratives corroborated the previous findings suggesting a level of practical saturation. Further, since the aim of the study was to expand on the concept of social differentiation of practices, even single examples that refute the idea of a homogenised practice perspective would serve as evidence of falsification, as argued by Flyvbjerg (2006) who negates the requirement of large random sample where one critical case is sufficient to prove or disprove a particular hypothesis. As an example in the present study, if an element of practice was recorded in an interview (i.e. religion or gender in shaping temporal or spatial practices), it exists and any blanket statements that overlook it, are negated.

Gram-Hanssen (2014) argues that within energy consumption studies, it is often preferable to combine a qualitative interview approach with actual measurements, not to validate what the interviewees say but to understand how the objective measurements relate to the subjective understanding of perceived indoor conditions and how measurements relate to the expressions of indoor-climate practices. Electricity use data of the interviewed households was collected from their electricity bills but comparison at this stage of the research was not possible due to inconsistency of the data ${ }^{2}$. Detailed quantitative measurements will be conducted in the next stage of the research.

\section{Findings}

Household practices were analysed using the conceptual framework of Shove and Pantzar (2005). The findings are presented here in relation to the material arrangements and socio-cultural dynamics of practices, especially in comparison to Western countries.

\footnotetext{
${ }^{2}$ With the same house size and metering system, the electricity consumption data varied considerably, in some cases up to 5.6 times. Where this can be attributed to disparities in occupants' energy-use, however the irregular meter readings, adjustments made to billing to account for line losses and other faults as accounted by the homeowners and evidenced in the bills made simple quantification through electricity bills inaccurate and unreliable.
} 


\subsection{Practices and material arrangements}

One key aspect that shapes homeowners' daily routines in Pakistan is the intermittent electricity supply system. Scheduled power outages for 6-10 hours during the daily 24-hour time-period mean that the Pakistani homeowners consistently rearrange their energy-use practices to accommodate the shifting magnitude and frequency of load-shedding schedules:

"We had to make changes and adjustments because of it (load-shedding) obviously. We had to schedule when to do the laundry according to power outage times. We think about every part of our routine based on when the light will be out and when it will come back. We have had to manage and set our entire day according to it. Everyone has done that. This is an issue which we have been facing for many years now, so we have had no choice but to do this. Now we have all become very much used to it." (Interview A)

"We have to plan- when we have electricity, we think okay, I need to do this, and this and that before the electricity goes out. Most often, it's the ironing I have to worry about. The maid also has to consider the electricity hours." (Interview J)

Shortages in electricity and load-shedding schedules mean that homeowners are acutely aware of the presence (or absence) of electricity. The continuous availability of electricity in the developed world can result in disengagement with energy (Pierce and Paulos, 2010) due to its 'invisible, unremarkable and unrecorded' (Warde and Southerton, 2012, p. 6) nature. Contrary to this, Pakistani homeowners' engagement with electricity was much more meaningful and grounded in material reality (through the various systems of electricity provision described below):

"The first thing I do after I get up is to switch off all the lights that were on during the night... I don't think we are careless users. All of us take care that if a light isn't being used, we do switch it off." (Interview B)

Switching off lights for saving electricity was common among most of the homeowners. Tangibility of electricity in this regard is high. This can be observed in Urdu conversation, where the term 'light' is used to interpret 'electricity', and electricity consumption is a common topic of discussion because of load-shedding;

"Here, if you have to go visit someone, they will tell you their electricity schedules, so that you don't end up visiting them at a time when there isn't any electricity in the house. You must have come across such jokes as well that Pakistanis now talk in terms like, 'So is your's there?', 'Ours isn't there!'. We have become so used to this! We are going back in time, back to the stone age!" (Interview $\mathrm{H}$ ) 
The electricity bill is also a common topic for conversation, a recurring concern voiced by all Pakistani households. Awareness of the monthly billing is a matter of importance for everyone in a household:

"We all look at it. The older son pays the bill. We all look at the amount, not in greater detail. Dua looks at it quite thoroughly. That's because there was a problem with it once. It came up to PKR 24,000. That was too much. No one among the neighbours had such a high amount." (Interview D)

Where dependency on an intermittent supply has made homeowners more flexible and resilient in managing their day to day practices; conversely, it has also led to the emergence of a new material culture in households to seek continuation and stability of practices. All households interviewed had mechanisms for localised electric power generation or storage for periods of load-shedding. These included UPS (Uninterrupted Power Supply) systems (Fig. 1), generators and more recently, Solar Photovoltaic (PV) systems (Fig. 2).

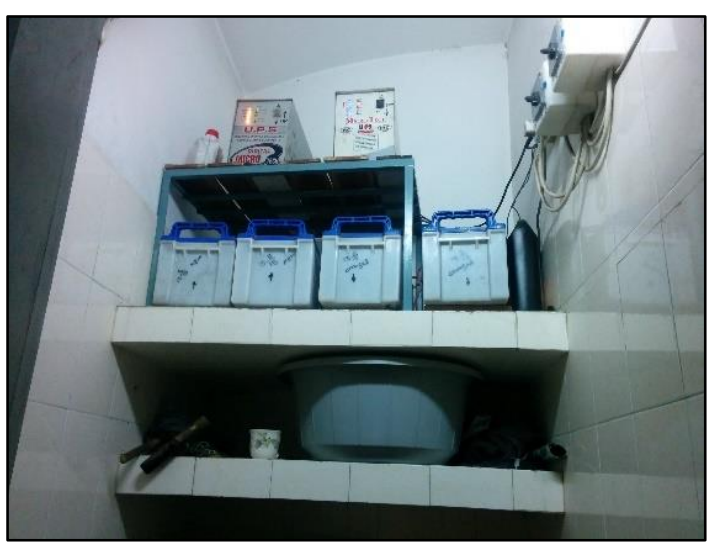

Figure 1: UPS system (Interview A)

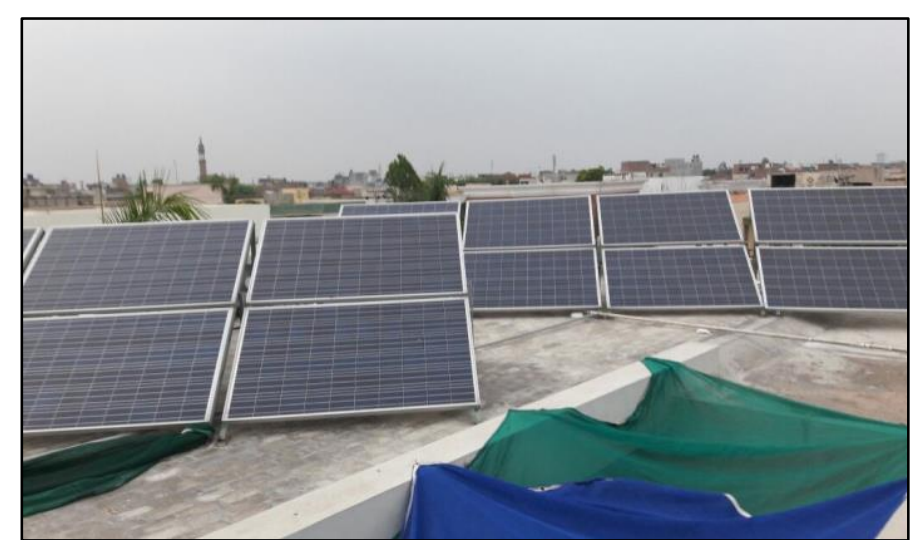

Figure 2: Solar PV system (Interview F)

In addition to back-up systems, the type of appliances and equipment selected and used is very much dependent on energy regime. This was evident in the use of energy efficient lighting such as LEDs (Light Emitting Diodes) and CFLs (Compact Fluorescent Lights), which are better compatible with load-shedding, as more lights can be switched on and for longer on microgeneration/battery power. Fluctuation in voltage also makes use of CFLs less suitable than LEDs and was cited by one homeowner as the reason behind its installation;

"One thing is that they give much more light than the usual simple (conventional) bulbs, secondly, in Pakistan as u know there is load-shedding, so the simple bulbs don't have that long life, so one advantage that these bulbs have is that when there is sudden failure, the concentration of light is maintained. Also...if the voltage gets high suddenly, or drops, these bulbs fuse, you must know, they just blast. The others don't do this." (Interview A) 
The interviews suggest that electricity, and more broadly energy, plays an intrinsic role in the decision-making of Pakistani households; from the myriad of material elements for electricity storage and generation that define what practices can be undertaken to the load-shedding schedules that determine when these practices can be performed. As such, electricity (and energy in general) becomes more a material component of everyday practices. A similar conceptualisation of energy has been put forth by Strengers (2012) who argues that integration of smart metering and demand management systems provide examples of the collapsing supply-demand divide in which 'electricity systems become an active element in the practices they enable' (p. 230). Where the present study serves as a case in point for this proposition, future systems will only serve to strengthen the conceptualisation of energy as a material element within everyday practices.

Apart from the electricity provision system and individual electric appliances, another material component that shapes everyday practices are physical spaces where these practices take place, the domestic architecture itself. During the interviews, a question surfaced on what kinds of practices does the physical structuring of contemporary design normalise or prefigure? Alternatively, how has current domestic architecture adapted to evolving practices?

The historic trajectory of house design in Lahore has evolved from a vernacular architecture with a traditional central courtyard design, based on sensibilities of simplicity, functionality, passive means of comfort and cultural norms to a compact, dense, deep-plan configuration of concrete, glass and brick masonry conforming to the modern movement (Mumtaz, 1985). Vernacular architecture was characterised by the use of passive techniques and indigenous materials such as thick brick masonry walls plastered with lime mortar, high ceilings and small windows near the ceilings that acted as ventilators and resulted in comfortable indoor temperatures and passive cooling of houses.

In the present case-study, evidence of the dichotomic interdependence between architectural spaces and household practices surfaced during conversation with the homeowners:

"We wanted a spacious home, that is why we designed very wide, big windows, so that we get lots of daylight and fresh air, as air-conditioning wasn't very popular and conventionally used in those days. As time passed, and ACs were installed, we realised that the windows are very big, so we had to reduce the size of the windows of the entire house, both length wise and breadth wise" (Interview F).

"Well, in the summers, we do have this problem, that the lounge is too big, and the stairs to the first floor open directly into it, so we cannot really cool this space. We do think about installing glass doors or a separation for the stairwell, so that we can 
make the lounge more comfortable, as that is the most used room in the house." (Interview C)

This results in conflicting requirements where openness competes with space cooling. Windows are often blocked externally with green cloth or bamboo blinds to prevent excessive heating in summers, as evidenced in the case studies:

"The thing is, in my room I don't have any system for daylighting, because we have covered the windows with shades externally to stop heat and sunlight getting in. In the kitchen, when we have sufficient light, then we don't use artificial lights till that time, but then when the cooking needs to be done, then we have to use lights. We don't get a lot of daylight inside the rooms." (Interview G)

Six of the ten households interviewed could not use their open-plan living rooms in summer due to a lack of appropriate thermal control. This results in the master bedroom functioning as a multipurpose space:

"My bedroom, this is now our lounge, our living room, our bedroom, our dining room, we practically do everything here! Especially now in the summers, as the AC is on here, so everyone stays here. If we switch on the AC in the lounge, as its open from all sides, it takes so much time for it to become comfortable" (Interview E)

This is an example of how contemporary houses, preferred by middle class households in countries like Pakistan, can facilitate inefficient practices that lead to reliance on air-conditioning for thermal comfort. These findings echo those of Wilhite's (2008) and Sahakian's (2014) historic review of air-conditioning in southern India and Southeast Asia respectively, where natural cooling techniques and traditional house design were overthrown by the onset of modern 'Westernised' architectural practices. Alternatively, Nicol and Humphreys' (2002) study of comfort conditions in buildings in Pakistan shows how passively designed buildings not only reduce the electricity profiles, but also help to improve the 'adaptive opportunity' offered to occupants.

One adaptive measure most homeowners were found to take in the present study was the variance in space usage patterns in different seasons, particularly the use of the first floor was often put on hold in hot summer months because of very high indoor temperatures:

"In winters, all the upstairs rooms are in use. But in summers, we try to use only one room. So, the other children sleep in my daughter's room downstairs, on mattresses on the floor, so that one $\mathrm{AC}$ is on... this is only to make sure that the electricity bill isn't too high." (Interview J) 
Privacy is an important issue for most of these middle class homeowners, particularly for the females, who are usually subject to religious and cultural norms of $h i j a b^{3}$ and require segregation of spaces or planning in a way that maintains privacy. In this regard, open-plan houses fashionable in contemporary Western architecture, and now gaining popularity in Pakistan (six out of ten casestudy households), often prove incompatible with the identified cultural and moral sensibilities (Figs. 3 and 4). Mrs. Furqan:

“The TV lounge didn't have any partitions. This entire area used to be one big open space. The house was planned such that the kitchen and dining room both open into the lounge, they are linked through the lounge basically. This causes a problem for me. When we have guests over, and we are very social, the house staff has to cross the lounge to reach the dining area, which becomes uncomfortable for some guests." (Interview F)
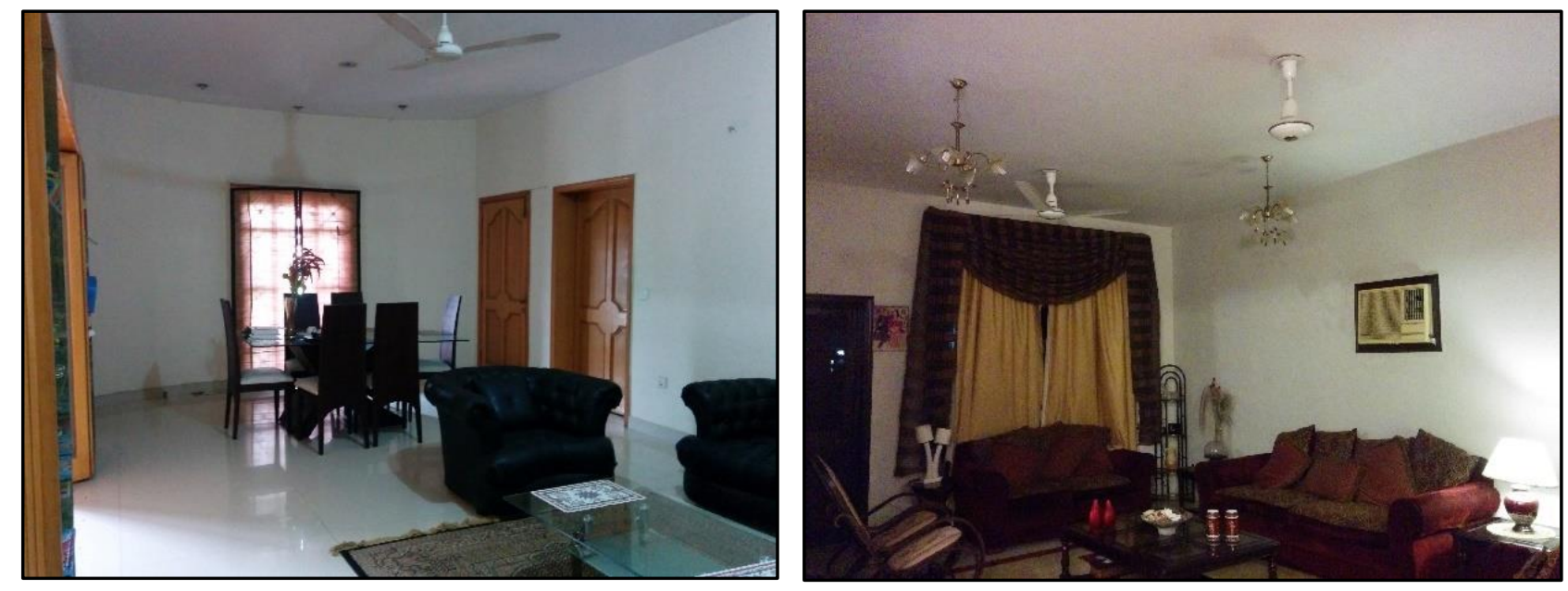

Figure 3 and Figure 4 : Large open-plan living rooms (Left: Interview E; Right: Interview F)

Provision of a central courtyard has been a key aspect in vernacular Pakistani architecture, in keeping with traditional Islamic architecture. Such courtyards provided a private open space for homeowners, particularly women, to carry out numerous daily practices, not only ensuring privacy but also a connection to outdoors. The contemporary house design, as in the case studies, has all but severed the connection of the indoor with the outdoor space. Outdoor spaces are very limited and designed in a manner, which makes them unusable to most homeowners owing to cultural issues of privacy and impracticality. Low boundary walls and the absence of parapets on terraces are in contradiction with the need for privacy by most homeowners. Mrs. Asim:

\footnotetext{
${ }^{3}$ Covering of the head and modest loose clothing. In Pakistani culture, a dobatta- large piece of cloth to cover the head and torso- is traditionally worn by women in public.
} 
"For me, it's also for privacy! I like that the curtains remain drawn always!... We can go and sit outside, but there is no privacy. I am thinking of doing something on the terrace for that. If you sit in the garage, there is no privacy." (Interview A)

Browne (2016), in reviewing hygiene practices in China, explains how the transformation of the urban fabric led to an evolution of not just the materiality, but the sociality of the practices. With current connections between indoors and outdoors severed by modern house designs, many outdoor practices have become obsolete, as explained by Mrs. Harris:

"Outdoor sitting practice was much more...to sit outside in the lawn. My father loved fruits, so instead of a lawn we had a fruit garden. My brother used to harvest honey bees as well. For studying, we would bring out small tables as well. We would switch on pedestal fans, even have tea outside. Now this practice has died away." (Interview H)

The provision of a second kitchen upstairs in joint family households provides another example of the disparity between the designed spaces and daily practices in Pakistani households (see section 4.2). These findings support Schatzki’s (2011) views on practices and arrangements: prefigurations in material and social arrangements make 'some actions, inter alia, easier and harder or more direct or circuitous than others' (p. 10). Hence, prefiguration within spatial arrangements conditions and competes with the various images, skills and (other) materiality that define the performance and adaptability of current and future practices.

\subsection{Socio-cultural dynamics in everyday practices}

The interviewed homeowners often referred to their practices in relation to wider social and cultural contexts, such as expectations and acceptance of their practices within their neighbourhood. They mentioned how their practices typically echoed those of their neighbours and how certain actions, being common, then became justified in society. Mrs. Gulzar justified having an illegal gas regulator installed in her house because her neighbours had done so as well:

\footnotetext{
"There are nine regulators on their (referring to her neighbours) wall!... It's not legal, it's against the law. You see, they are in bed with the line-men. They give them money. Now, I have installed one as well and you know what, the Sui gas people said to me everyone on this street has one installed, you can install one too..." (Interview $\mathrm{G}$ )
}

The interviews suggest that social image plays a significant role in household decision making in these middle-class households. For example, the exterior of the house in Pakistan can often provide judgements of economic, as well as social and cultural capital of homeowners; in the language of Bourdieu (1984): a visual display of the 'judgement of taste'. Those homeowners who were found 
to generally lay more emphasis on social perceptions (Interview A, G and I), had more elaborate and decorative house exteriors. Social image also plays a critical role in the interior. This is explicitly portrayed in the décor of the drawing room, a space designed for socialising, but also evident in other, more implicit means. Mrs. Asim presented a prime example of this when discussing her desire for buying a fourth refrigerator for the household:

\footnotetext{
"You know what my son's major concern is regarding this. He says what will people say? That they are so wasteful? They have four fridges in their house?! From the beginning, he says what will people say? When my friends come over, what will they say, why we have three, four fridges in our kitchen? There shouldn't be more than one or two." (Interview A)
}

This concept has been highlighted by Wilhite and Lutzenhiser (1999, p. 281), who state that 'necessary' consumption often becomes a mark of social accomplishment and standing. A homeowner who had recently installed solar panels and replaced all lights with LEDs, still had four window air conditioners installed that are commonly known to be inefficient. Although no reason was provided by the homeowner for not up-grading the ACs, one possible answer could be the lack of 'conspicuousness' which, as has been highlighted by Wilhite and Lutzenhiser (1999), can play a significant role in energy retrofit decision-making.

One key finding unique was the emergence of religious factors in relation to daily routines and practices of middle-income Pakistani homeowners. Religion was brought up explicitly by eight of the ten homeowners as a constituent of their daily practices - reasoning for their doings and sayings. Moreover, its influence on temporal arrangement of practices within the households was evident. Mrs Asim had a completely different routine for Fridays than the rest of the week, because of the Friday congregational prayer:

"I typically do the laundry daily, except for Fridays... On Fridays, I normally try not to use it...because of the water issue. Everyone has to use water in the washrooms so I don't want there to be shortage. Also, all the attention is mostly concentrated on that (the Friday congregation). Even my cooking on Fridays starts after 3pm." (Interview A)

Sustainability has recently been linked to religious perceptions in Western literature (Finlay and Palmer, 2003; Berry, 2013, 2014 among others), although the concept is not new (White, 1967). In the Global South, Wilhite (2008) reflects on the lack of conflicting political and religious ideologies in southern India, both of which seem to promote (or at least accept) increasing levels of consumption. In this case-study, however, religion, or at least the ideologies or rituals that it dictates, seems to be rooted within the frameworks of sustainability; 
"I do believe that we shoudn't waste water. We do try to avoid wastage, in any form...The reason that motivates us isn't because of the environment, but I think more on religious basis...we know that we cannot be good human beings if we are wasting things...it's wrong, it's not the right thing to do...that's what our parents taught us." (Interview F)

"I believe that nothing should be used more than is necessary, even if you have excess of anything. It's our religious obligation, you know." (Interview E)

Where social and cultural factors can be underpinned as 'capitals' in Bourdieu's framing of practices, in the context of this case study, religion can be seen as a form of cultural capital, since religion stands as an institution in its own right in Pakistan, and the acquisition of religious knowledge is deemed honourable and esteem-worthy. This offers potential for policy formation and marketing interventions, or engaging religious groups as intermediates in policy implementation. One such example in Pakistan was seen in the public campaign for cleanliness in Islamabad. With slogans of a well-known Hadith ${ }^{4}$, 'cleanliness is half of faith', the campaign aimed to reduce trashing and throwing garbage on the streets through religious motivation. Drawing on this perspective, it could be argued that if economic, or social and cultural capital drive consumption, exploring how acquisition of elevated 'religious capital' or, using a broader term, 'spiritual capital' might serve to regulate consumption in these middle-class households could prove to be beneficial. Narrowing the perspective from the wider neighbourhood community to the internal workings of the household itself, it becomes evident that complex family dynamics play an important role in how daily practices and domestic routines unfold. In Pakistan, as in broader South Asia, family has fundamental social importance, as Wilhite (2008) posits in his study of southern India, 'consumption invokes family, and family networks are important to acquisition of goods' (p. 165). The modern day urban society of Pakistan has evolved from intertwined ideologies of acceptable progression and valued stability. Abdul Qadeer (2006) articulates this unique socio-cultural transformation by positing that 'in the consumption and adoption of new products, Pakistanis respond opportunely, but in family values, gender relations, and political and religious beliefs they tack close to traditions in meaning and function, even if not in form.' (p. 137).

Cultural norms in Pakistan dictate the establishment of joint family systems; when a son is married, the bride is expected to move into her husband's house with his family. Often the married son and his growing family are allocated the upper floor of the house. In three of the six joint families interviewed, a separate kitchen was provided on the first floor for use by the second married couple

\footnotetext{
${ }^{4}$ Hadith is the term used to denote the collection of sayings of the prophet Muhammad which, with accounts of his daily practice (the Sunna), constitute the major source of guidance for Muslims that supplement the holy book, Quran.
} 
(Figs 5 and 6); however, in all three cases, it was not being used for daily cooking, as preparing proper meals is considered a joint practice. Where it would be unheard of for a son to live separately from his parents when residing in the same city, cooking and eating meals separately when residing in the same house would also be frowned upon by society, hence the lack of use of the allocated kitchen space, which merely provides symbolic independence.
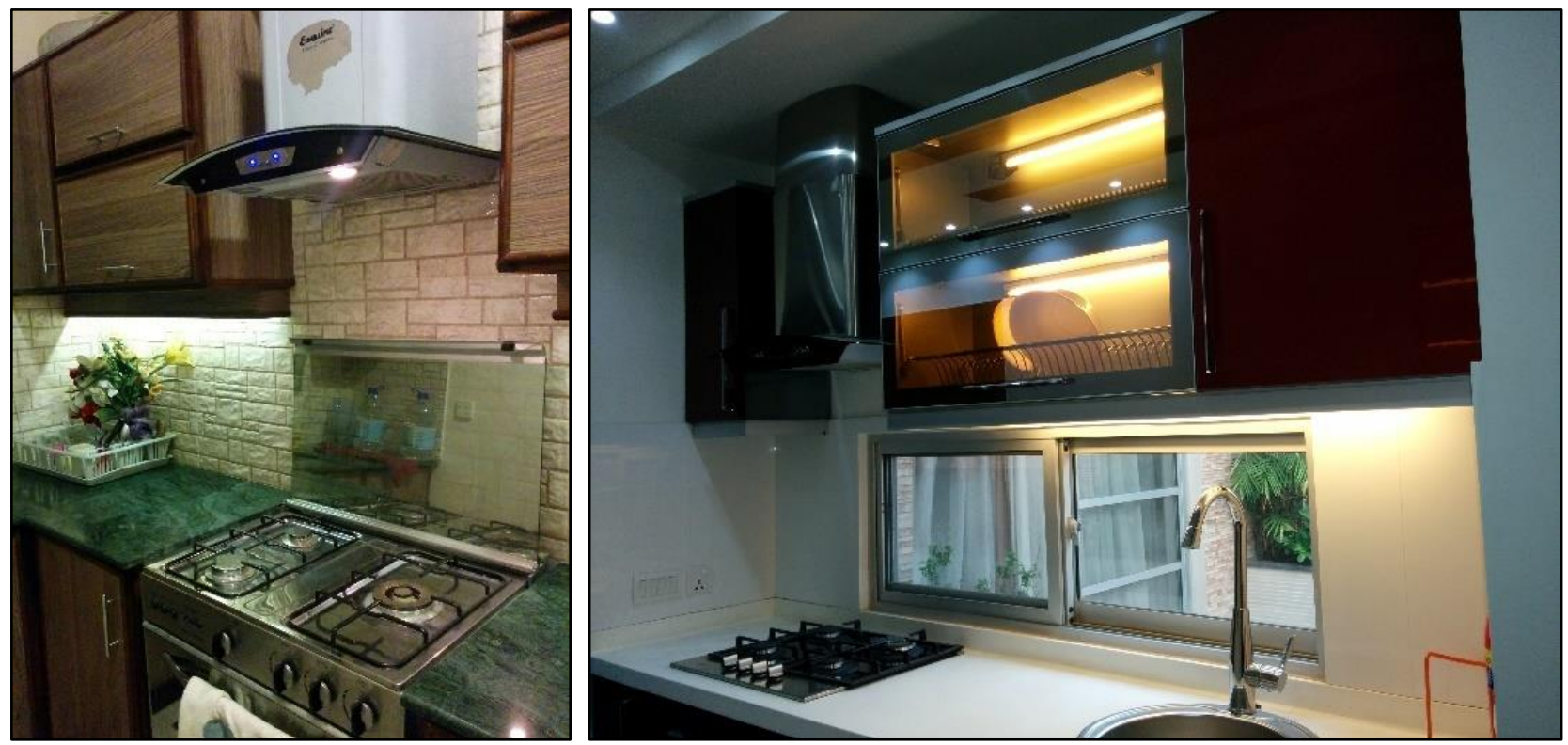

Figure 5 \& Figure 6: Separate kitchen on first floor, not in use. (Left: Interview F; Right: Interview I)

The older generation (those in their 40-60s) in joint families were found to be more conscious of their electricity use compared to the younger generation (10-30 age group):

“The children mostly don't bother. They are usually too busy in their studies to bother. I am the one who is mostly looking after the house, or if my husband is home, he also does some things. The children are least bothered, even if there is dust, or cobwebs, or even mould, they don't bother!" (Interview B, Mrs Bashir-aged 46)

“The children don't care much either. For example, in my daughter's washroom, one switch controls six lights, so if there is load-shedding and they aren't working then, when the electricity returns, they remain on after that. If this happens at night, after she has gone to sleep, then all six light bulbs remain on all night long." (Interview H, Mrs Harris-aged 53)

As per traditional norms, the house is considered the primary domain of the female, where most practices are partaken as an assertion to her authority. However, within these middle-class Pakistani households, the role allocations between the genders result in certain dichotomies within the household. For instance, the selection of household appliances and equipment, and the control of 
thermostat settings for air-conditioning were delegated to the males in nine of ten households. Cleaning and washing were all-female practices in all households. Cooking was predominantly delegated to the females. Hence, even though women are responsible for much of the housework, decision-making is a predominantly male domain:

“...my father and I, we are out most of the day, so everything in the house is being managed by the ladies of the house. We only come into play where some facilitation is required... In most cases, if an equipment or energy decision has to be made, it comes from us, but what is required, comes from them... These are the decisions that we make...if they want a TV in their room, they would tell us that they want a $\mathrm{TV}$, and we have to give it to them." (Interview F)

Such gendered role attribution was found quite similar to Wilhite's (2008) study of households in southern India, drawing on religious perceptions and social norms of chastity, obedience and self-sacrificing traits as idealised for women. Corroborating these findings, in the midlle-class Pakistani households, females generally displayed a tendency to be more careful in their consumption practices. This is not surprising given the cultural and traditional values of patience and tolerance that are instilled into females since early childhood, and are considered an essential component of the female persona. A fitting example of this was seen in Mrs Bashir and Mrs Chishti:

“... if I am alone in the house, then I don't put it (AC) on for myself solely. I don't feel it's justified for one person only. I just use the fan, making sure hot air doesn't permeate the house, that's it." (Interview B)

"Yes, I take care very much. Especially in using electricity for my own personal practices. For instance, if someone tells me to use the AC for myself alone in the room, I never do that! I do try not to use any extra for my own self.” (Interview C)

However, this trait was more commonly found in the older generation and was not as clearly evident in the younger generation, which portrays the infusion of shifting global trends towards equality and lesser gender disparities within the educated middle-income urban households.

\section{Conclusions}

This research used a practice-based framework for analysing middle-class household electricity consumption in the material and socio-cultural context of a developing country, taking Pakistan as a case study. Based on semi-structured, in-depth interviews and observations in the households, the research highlights the complex interconnected nature of electricity-use in everyday practices that are shaped by the material and socio-cultural arrangements within households and within the wider 
community. Understanding of electricity-use through 'homely' household practices helped to unfold the otherwise uncertain, unpredictable and therefore 'uncanny' electricity demand.

Materiality in its varying forms (e.g. energy infrastructure, Western influenced homes with open plans and individual electrical appliances) plays an intrinsic role in shaping, and in turn being shaped by, everyday household practices of Pakistani homeowners. Load-shedding and ways to overcome it have made electricity tangible for Pakistani households and influence spatial and temporal arrangements of domestic practices like laundering and ironing. The electricity provision system with its' shortcomings makes electricity tangible and meaningful to homeowners. The Western inspired architectural design and layout of the house, as preferred by the middle-class, determines what practices can be performed and where, and restrict the use of outdoor space due to cultural conventions like privacy - similarly, notions of privacy and gender segregation mean closed curtains and relying on artificial lighting during the day. These energy intensive modernistic prefigurations can conflict with everyday practices. This was seen, for instance, in uninhabitable living room spaces in summer, as their open-plan meant that localised cooling was not an option, and in the disconnect between indoor and outdoor spaces, which serves to transform the materiality as well as sociality of practices.

The interviews suggest that social and cultural structures of society, from the wider social and cultural expectations and acceptance of practices within the neighbourhood community, to religious meanings and ideologies that define the spatiotemporal arrangements of everyday life, and to joint family structures, age disparities and gender roles, have a profound effect on households' daily practices. The socio-cultural context is clearly distinct from Western countries and therefore also the practices themselves differ. This is demonstrated not only in explicit physical forms such as house décor, but in implicit ways, such as the number of appliances deemed 'socially acceptable', and in maintaining the standards and conspicuousness of 'necessary consumption'. Decisionmaking, purchase of appliances and setting the thermostat were explicitly male-dominated in the case study while practices like cooking and cleaning were performed by females. Understanding gender disparities between material purchases in public domain (men) and their domestic use (women) could help to answer broader questions such as why certain policies do not work as intended. The interviews show that women are in a key role in domestic energy management in Pakistan, raising the question of equity (Carlsson-Kanyama and Linden, 2007), since domestic energy saving actions advocated by policies (e.g. load-shedding) have more impact on women than on men.

This study aimed to expand the understanding of how practice theories can conceptualise electricity demand in developing countries. The application of practice theories in the present case study 
context revealed two aspects; firstly, the current conceptual understandings of practices and potential interventions, based on studies of consumption in the Western countries, cannot be applied as such in developing countries when the performances of practices differ due to socio-cultural aspects like joint family structures and notions of privacy. Secondly, while most energy consumption studies using theories of practice build on Schatzi (1996, 2001) and Reckwitz (2002), adopting their lack of emphasis on socio-economic dimension, this study suggests that Bourdieu's $(1984,1997)$ notions of class and capital could help to understand better the social differentiation of practices, preferences and norms that can be rooted in notions of socio-economic setting.

Interventions to transform domestic practices in middle-class households in developing countries will be explored in the next stage of the research but three ideas emerged during this study. Firstly, the potential of reconfiguring spatial arrangements could be investigated by studying applications from vernacular architecture, in order to make the middle-class housing typology more compatible with climatic as well as socio-cultural requirements. This would also serve to encourage more passive means of comfort. Secondly, policy frameworks should draw not just from the economic but also social and religious capital as motivation for domestic energy efficiency, as seen in the example of public campaigns of cleanliness in Islamabad. Thirdly, at more general level, policymakers in developing countries need to take account that 'uncanny' domestic electricity demand is an outcome of mundane, daily routines and consumption practices that are interconnected to the multiple levels of material and social structures that need to be understood in order to formulate an effective and legitimate policy.

\section{Acknowledgements}

This work is part of a $\mathrm{PhD}$ research at the University of Cambridge, funded by Vicky Noon Cambridge Scholarship under the Cambridge Commonwealth, European \& International Trust.

\section{References}

Abdul-Qadeer, M., 2006. Pakistan: Social and Cultural transformations in a Muslim nation. London; Newyork: Routledge.

Alahdad, Z., 2012. Pakistan's energy sector: From crises to crises- breaking the chain, Islamabad: Pakistan Institute of Development Economics.

Bennett, T. et al., 2009. Culture, Class, Distinction. London and New York: Routledge.

Berry, E., 2013. Religious Environmentalism and Environmental Religion in America. Religion compass, 7(10), pp. 454-466. 
Berry, E., 2014. Religion and Sustainability in Global Civil Society: Some Basic Findings from Rio+20. Worldviews, Volume 18, p. 269-288.

Bourdieu, P., 1977. Outline of a Theory of Practice, New York: Cambridge University Press.

Bourdieu, P., 1984. Distinction: A Social Critique of the Judgement of Taste. Cambridge(Massachusetts): Harvard University Press.

Bourdieu, P., 1997. The Forms of Capital. In: A. H. Halsey, H. Lauder, P. Brow \& A. S. Wells, eds. Education: Culture, economy, and society. Oxford: Oxford University Press, pp. 280-291.

Browne, A. L., 2016. Histories, Trajectories and Patterns of Cleanliness, Energy and Water Consumption: Reflections on China. Lancaster, DEMAND Centre Conference.

Carlsson-Kanyama, A. \& Linden, A., 2007. Energy efficiency in residences - challenges for women and men in the North. Energy Policy, Volume 35, pp. 2163-2172.

Darmon, I. and Warde, A., 2016. Senses and sensibilities: stabilising and changing tastes in cross-national couples, 19(4):. Food Culture \& Society, 19(4), pp. 705-722.

EIA, 2016. U.S. Energy Information Administration, Independent Statistics and Analysis. http://www.eia.gov/tools/glossary/index.cfm?id=E [Accessed 2305 2016].

Finlay, V. and Palmer, M., 2003. Faith in Conservation: New Approaches to Religions and the Environment (Directions in Development - Human Development). 1st ed. Washington, D.C.: World Bank Publications.

Flyvbjerg, B., 2006. Five Misunderstandings About Case-Study Research. Qualitative Inquiry, 12(2), pp. 219-245.

Foulds, C., Robison, R. A. \& Macrorie, R., 2017. Energy monitoring as a practice: Investigating use of the iMeasure online energy feedback tool. Energy Policy, Volume 104, p. 194-202.

Frued, S., 1919. The 'Uncanny'. In: J. Strachey, ed. The Standard Edition of the Complete Psychological Works of Sigmund Freud. An Infantile Neurosis and Other Works. London: Hogarth Press, pp. 217-256.

Galvin, R., 2015. How many interviews are enough? Do qualitative interviews in building energy consumption research produce reliable knowledge?. Journal of Building Engineering, Volume 1, pp. 212 .

Galvin, R. and Sunikka-Blank, M., 2016. Schatzkian practice theory and energy consumption research: Time for some philosophical spring cleaning?. Energy Research \& Social Science, Volume 22, pp. 63-68.

Giddens, A., 1984. The Constitution of Society: Outline of the Theory of Structuration. Cambridge: Cambridge: The Polity Press.

Gram-Hanssen, K., 2008. Consuming technologies, developing routines. Journal of Cleaner Production, Volume 16, pp. 1181-1189.

Gram-Hanssen, K., 2010. Residential heat comfort practices: understanding users. Building Research and Information, 38(2), pp. 175-186. 
Gram-Hanssen, K., 2011. Understanding change and continuity in residential energy consumption. Journal of Consumer Culture, Volume 11 (1), p. 61-78.

Gram-Hanssen, K., 2014. New needs for better understanding of household's energy consumption behaviour,lifestyle or practices?. Architectural Engineering and Design Management, 10(1-2), pp. 91107.

Halkier, B. and Jensen, I., 2011. Doing 'healthier' food in everyday life? A qualitative study of how Pakistani Danes handle nutritional communication. Critical Public Health, 21(4), pp. 471-483.

Halkier, B., Katz-Gerro, T. \& Martens, L., 2011. Applying practice theory to the study of consumption: Theoretical and methodological considerations. Journal of Consumer Culture, 11(1), p. 3-13.

Hand, M., Shove, E. \& Southerton, D., 2005. Explaining Showering: a Discussion of the Material, Conventional, and Temporal Dimensions of Practice. Sociological Research Online, 10(2).

Hargreaves, T., 2011. Practice-ing behaviour change: Applying social practice theory to proenvironmental behaviour change. Journal of Consumer Culture, 11(1), pp. 79-99.

HDIP, 2015. Pakistan Energy Yearbook 2014. Islamabad: Ministry of Petroleum and Natural Resources, Government of Pakistan.

HIES, 2015. Household Integrated Economic Survey (HIES) 2013-14, Islamabad: Pakistan Bureau of Statistics.

http://www.pbs.gov.pk/sites/default/files//pslm/publications/hies2013_14/hies_complete_report_2013_14 .pdf. [Accessed on 1706 16]

Higginson, S. et al., 2015. Diagramming social practice theory: An interdisciplinary experiment exploring practices as networks. Indoor and Built Environment, 24(7), p. 950-969.

Karakosta, C. and Askounis, D., 2010. Developing countries' energy needs and priorities under a sustainable development perspective: A linguistic decision support approach. Energy for Sustainable Development, Volume 14, p. 330-338.

Karvonen, A., 2013. Towards systemic domestic retrofit: A social practices approach. Building Research and Information, 41(5), pp. 563-574.

Kreft, S. et al., 2015. Global Climate Risk Index 2015, Berlin: GermanWatch e.V., German Federal Ministry for Economic Cooperation and Development (BMZ)

https://germanwatch.org/en/download/10333.pdf [Accessed on 2302 2016]

Kuijer, L. and Bakker, C., 2015. Of chalk and cheese: behaviour change and practice theory in sustainable design. International Journal of Sustainable Engineering, 8(3), pp. 219-230.

Kuijer, L., Jong, A. d. and Eijk, D. V., 2013. Practices as a Unit of Design: An Exploration of Theoretical Guidelines in a Study on Bathing. ACM Transactions on Computer-Human Interaction (TOCHI), Sepember, Volume Vol. 20, No. 4, Article 21, p. 22.

Maller, C., 2011. Practices involving energy and water consumption in migrant households. In: Urban Consumption. Collingwood, Australia: CSIRO Publishing, pp. 237-250. 
Maller, C., Horne, R. and Dalton, T., 2012. Green renovations: Intersections of daily routines, housing aspirations and narratives of environmental sustainability. Housing, Theory and Society, 29(3), pp. 255275.

Marres, N., 2011. The costs of public involvement: everyday devices of carbon accounting and the materialization of participation. Economy and Society, 40(4), pp. 510-533.

Matsuhashi, N., Kuijer, L. \& Jong, A. d., 2009. A Culture-Inspired Approach to Gaining Insights for Designing Sustainable Practices. Sapporo, Japan, The Japan Society of Mechanical Engineers.

Mumtaz, K. K., 1985. Architecture in Pakistan. Singapore: Concept Media Pte Ltd.

Nicol, J. F. and Humphreys, M., 2002. Adaptive thermal comfort and sustainable thermal standards for buildings. Energy and Buildings, Volume 34, pp. 536-572.

Palm, J. and Reindl, K., 2016. Understanding energy efficiency in Swedish residential building renovation. Energy Research \& Social Science, Volume 11, pp. 247-255.

Pierce, J. and Paulos, E., 2010. Materializing Energy. Aarhus, s.n., pp. 113-122.

Powells, G., Bulkeley, H., Bell, S. \& Judson, E., 2014. Peak electricity demand and the flexibility of everyday life. Geoforum, Volume 55, pp. 43-52.

Purhonen, S. et al., 2014. Purhonen S, Gronow J, Heikkilä R, Kahma N, etal. (2014) Suomalainen maku: kulttuuripääoma, kulutus ja elämäntyylien sosiaalinen eriytyminen [The Finnish Taste: Cultural capital, consumption and the social stratification of lifestyles].. Helsinki: Gaudeamus Helsinki University Press.

Reckwitz, A., 2002. Toward a Theory of Social Practices: A Development in Culturalist Theorizing. European Journal of Social Theory, 5(2), p. 243-263.

Reckwitz, A., 2012. Affective spaces: a praxeological outlook. Rethinking History: The Journal of Theory and Practice, 16(2), pp. 241-258.

Rinkinen, J., Jalas, M. \& Shove, E., 2015. Object Relations in Accounts of Everyday Life. Sociology, 49(5), p. 870-885.

Rinkinen, J. and Smits, M., 2016. Conceptualising conjunctions: Understanding change in energy related practices in urban Southeast Asia. Lancaster, DEMAND Centre Conference.

Røpke, I., Gram-Hanssen, K. \& Jensen, J. O., 2008. Households' ICT Use In An Energy Perspective. Brussels, COST Office, p. 595-611.

Sahakian, M., 2014. Keeping Cool in Southeast Asia: Energy Consumption and Urban Air-Conditioning. Hampshire: Palgrave macmillan UK.

Savage, M. et al., 2013. A new model of social class: findings from the BBC's Great British Class Survey Experiment. Sociology, 47(2), p. 219-250.

Schatzki, T., 2001. Introduction. In: T. Schatzki, K. K. Cetina \& E. v. Savigny, eds. The Practice Turn in Contemporary Theory. Taylor \& Francis e-Library: Routledge (Taylor \& Francis Group), pp. 1-14.

Schatzki, T., 2011. Where the Action Is (On Large Social Phenomena Such as Sociotechnical Regimes). Sustainable Practices Research Group Working Paper 1, November. 
Schatzki, T. R., 1996. Social Practices: A Wittgensteinian Approach to Human Activity and the Social. Cambridge: Cambridge University Press.

Schmidt, S. and Weigt, H., 2015. Interdisciplinary energy research and energy consumption: What, why, and how?. Energy Research \& Social Science, Volume 10, pp. 206-219.

Shaikh, H., 2016. Housing inequality in Pakistan: The case of affordable housing, Lahore: International Growth Centre (IGC). http://cdpr.org.pk/wp-content/uploads/2016/02/IGC-Pakistan-2016-Policy-note.pdf [Accessed 1809 2016]

Shove, E., 2010. Beyond the ABC: climate change policy and theories of social change. Environment and Planning , 42(A), pp. 1273- 1285.

Shove, E., 2014. Putting practice into policy: reconfiguring questions of consumption and climate change. Contemporary Social Science, 9(4), pp. 415-429.

Shove, E. and Pantzar, M., 2005. Consumers, Producers and Practices: Understanding the invention and reinvention of Nordic walking. Journal of Consumer Culture, 5(1), p. 43-64.

Shove, E., Pantzar, M. \& Watson, M., 2012. The Dynamics of Social Practice: Everyday Life and how it Changes. London: Sage.

Shove, E. and Walker, G., 2014. What Is Energy For? Social Practice and Energy Demand. Theory, Culture \& Society, 31(5), pp. 41-58.

Shove, E., Watson, M. \& Spurling, N., 2015. Conceptualizing connections: Energy demand, infrastructures and social practices. European Journal of Social Theory, 18(3), p. 274-287.

Smits, M., 2015. Southeast Asian Energy Transitions: Between Modernity and Sustainability. Surrey, England ; Burlington, VT : Ashgate Publishing, Ltd.

Sovacool, B. K., 2014. What are we doing here? Analyzing fifteen years of energy scholarship and proposing a social science research agenda. Energy Research \& Social Science, Volume 1, pp. 1-29.

Sovacool, B. et al., 2015. Integrating social science in energy research. Energy Research \& Social Science, Volume 6, p. 95-99.

Strauss, A. L. and Corbin, J. M., 1998. Basics of Qualitative Research : Techniques and Procedures for Developing Grounded Theory. 2nd ed. Thousand Oaks, CA: Sage Publications, Inc..

Strengers, Y., 2012. Peak electricity demand and social practice theories: Reframing the role of change agents in the energy sector. Energy Policy, Volume 44, p. 226-234.

Strengers, Y., 2013. Smart Energy Technologies in Everyday Life: Smart Utopia?. 1st ed. Basingstoke, Hampshire: Palgrave Macmillan.

Vidler, A., 1992. The Architectural Uncanny: Essays in the Modern Unhomely. Cambridge, Massachusetts; London, England: MIT Press.

Warde, A., 2005. Consumption and Theories of Practice. Journal of Consumer Culture, 5(2), p. 131-153.

Warde, A. and Southerton, D. eds., 2012. The Habits of Consumption, COLLeGIUM: Studies across Disciplines in the Humanities and Social Sciences. Helsinki: Helsinki Collegium for Advanced Studies. 
Watson, M. and Shove, E., 2005. Doing it yourself? Products, competence and meaning in the practices of DIY. Torun, Poland, s.n.

White, L., 1967. The Historical Roots of Our Ecologic Crisis. Science, New Series, 155(3767), pp. 12031207.

Wilhite, H., 2008. Consumption and the Transformation of Everyday Life: A View from South India. New York: Palgrave Macmillan.

Wilhite, H. \& Lutzenhiser, L., 1999. Social Loading and Sustainable Consumption. Advances in Consumer Research, Volume 26, pp. 281-287.

Wilhite, H. et al., 1996. A cross-cultural analysis of household energy use behaviour in Japan and Norway. Energy Policy, 24(9), pp. 795-803.

Winskel, M., 2014. Embedding Social Sciences in Interdisciplinary Research: Recent Experiences from Interdisciplinary Energy Research. Science as Culture, 23(3), pp. 413-418.

Wolfram, C., Shelef, O. \& Gertler, P., 2012. How Will Energy Demand Develop in the Developing World?. Journal of Economic Perspectives, 26(1), pp. 119-138.

Yin, R. K., 2014. Case Study Research: Design and Methods. 5th ed. California, US: Sage. 